\title{
Designation of a New Type Strain for Listeria monocytogenes Request for an Opinion
}

\author{
DOROTHY JONES $^{1 *}$ AND H. P. R. SEELIGER ${ }^{2}$
}

Department of Microbiology, School of Medicine and School of Biological Sciences, University of Leicester, Leicester LEI 7RH, England, ${ }^{1}$ and Institut für Hygiene und Microbiologie, 87 Wurzburg, Federal Republic of Germany ${ }^{2}$

We request that strain ATCC 15313 be replaced by strain NCTC 7973 as the type strain of Listeria monocytogenes.

In accordance with Rule 18(i) of the International Code of Nomenclature of Bacteria (2), we request that the type strain of Listeria monocytogenes, strain ATCC 15313 (strain 53 XXIII of Murray), be replaced by $L$. monocytogenes NCTC 7973 (strain 58 XXIII of Murray). Strain ATCC 15313 was designated the type strain of $L$. monocytogenes by the late E. G. D. Murray at the Second Symposium on Listeric Infection held at Montana State College, Bozeman (3). At the time that he made the proposal, Murray was not aware of the fact that this strain does not exhibit beta-hemolysis on agar containing $5 \%$ ( $\mathrm{vol} / \mathrm{vol}$ ) sheep or horse blood incubated for up to $48 \mathrm{~h}$ at $37^{\circ} \mathrm{C}$. Lack of hemolytic activity by this strain is noted in the Catalogue of the American Type Culture Collection (1) and was confirmed recently in the nine laboratories which participated in the International Working Group for the Determination of Minimal Standards for the Genus Listeria. Furthermore, it has been recognized for some time that an increasing loss of surface antigens in strain ATCC 15313 has resulted in roughness which prevents adequate serotyping of this strain and makes it unsuitable for raising antisera.

Strains ATCC 15313 and NCTC 7973 were both studied in the project referred to above. Strain NCTC 7973 was isolated from the mesenteric node of a guinea pig during the original studies of Murray et al. (4). This strain is frankly hemolytic and has for several decades served as the reference strain for the preparation of $L$. monocytogenes $\mathrm{O}$ and $\mathrm{H}$ antisera of serovar $1 / 2 \mathrm{a}$ in the laboratory of H. P. R. Seeliger. In all other respects strains ATCC 15313 and NCTC 7973 are identical.
Our request that strain NCTC 7973 replace strain ATCC 15313 as the designated type strain of the species $L$. monocytogenes is made because of the importance of beta-hemolysis in the description of this species and, consequently, in the identification of new isolates. This character is of even greater importance since the description of nonhemolytic strains (previously designated $L$. monocytogenes serovar 6) as Listeria innocua (5). In addition, as noted above, strain ATCC 15313 can no longer be adequately serotyped.

We have prepared this request on behalf of and with the unanimous endorsement of the ICSB Subcommittee on the Taxonomy of Listeria.

\section{LITERATURE CITED}

1. American Type Culture Collection. 1982. Catalogue of the American Type Culture Collection, 15th ed. American Type Culture Collection, Rockville, Md. U.S.A.

2. Lapage, S. P., P. H. A. Sneath, E. F. Lessel, V. B. D. Skerman, H. P. R. Seeliger, and W. A. Clark (ed.). 1975. International code of nomenclature of bacteria. 1975 Revision. American Society for Microbiology, Washington, D.C.

3. Murray, E. G. D. 1963. A retrospect of Listeriosis, p. 2-6. In M. L. Gray (ed.), Second Symposium on Listeric Infection, Montana State College, Bozeman. Artcraft Printers, Bozeman.

4. Murray, E. G. D., R. A. Webb, and M. B. R. Swann. 1926. A disease of rabbits characterised by a large mononuclear leucocytosis caused by a hitherto undescribed bacillus Bacterium monocytogenes (n.sp.). J. Pathol. Bacteriol. 29:407-439.

5. Seeliger, H. P. R., and M. Schoofs. 1977. Serological analyses of non-haemolysing Listeria strains belonging to a species different from Listeria monocytogenes p. 24-28. In I. Ivanov (ed.), VII International Symposium on the Problems of Listeriosis, Varna, Bulgaria. National Agroindistrial Union Center for Scientific Information, Sofia. 